\title{
MODERNIZACIÓN Y REDEMOCRATIZACIÓN EN CHILE
}

\section{Alfonso Arrau Corominas}

\section{INTRODUCCIÓN}

Cómo renacen las democracias?, fue la pregunta con mayor gravitación en el campo de la sociología en América Latina durante la década de los 80. ¿Cómo se consolidan las democracias?, pareciera constituir la pregunta de los años 90 . Esta pregunta se valida por el hecho que el proceso de redemocratización se ha puesto en marcha en casi todos los países de América Latina. La Jécada perdida de los 80 a decir de la CEPAL, ha sido sucedida por el optimismo en torno al tema en los comienzos del 90.

No obstante las grandes diferencias entre los casos nacionales, el proceso apunta formalmente a la alirmación de la democracia en el marco de la tradición anglosajona, vale decir, un sistema representativo, institucionalmente autorregulado, de manera que la mayoría delega en una minoría la administración del Estado y el arte del Gobierno'. Entre las instituciones que normalmente se asocian a este sistema, dando origen a la noción de régimen democrático se distinguen: división de poderes, sufragio universal, pluralidad de partidos políticos, representación parlamentaria, estabilidad de cuadros burocráticos, opinión pública informada, políticas de bienestar social y control civil sobre fuerzas armadas.

En este contexto un sistema democrático consolidado es aquel en que todas o la mayoría de las instituciones señaladas tienen plena vigencia y hacen su particular contribución a la autorregulación del sistema.

Una aplicación simple del criterio de prueba recientemente definido pone en evidencia que las noveles democracias en América Latina están recién en proceso de despliegue institucional y que la consolidación democrática será una tarea de largo aliento. Dicho proceso pasa y pasará por enormes dificultades. De hecho, hoy se visualizan situaciones de alta incertidumbre. Argentina y Venezuela han sido sacudidas por intentonas golpistas; recientemente, el Perú fue objeto de autogolpe, etcétera.

El proceso de redemocratización, sus dificultades y desencantamientos requieren de la atención y reflexión crítica de las ciencias sociales.

Desde la sociología, el proceso subyacente y que constituye fuente sustancial de desafíos a la redemocratización está representado por el actual estadio de la modernidad. Este documento de trabajo constituye el punto de partida de una línea de investigación que intentará, por aproximaciones sucesivas, elaborar modelos de evaluación de políticas sociales y públicas en Chile en el marco de los desafíos de la modernidad vis-a-vis los procesos de redemocratización.

El propósito específico de este documento es formular algunas líneas problemáticas estructurales e institucionales heredadas de la experiencia de modernización autoritaria. En torno a dichas problemáticas se diversificará un conjunto de investigaciones empíricas.

El documento se inicia con algunas reflexiones relativas al actual estadio de la modernidad. En seguida se revisa la experiencia autoritaria a través de la lectura de dos estilos de pensamicntos con incidencia en el debate sobre la materia: el pensamiento neoliberal y el pensamiento desde las

\footnotetext{
${ }^{1}$ Una discusión actualizada sobre la denocracia, en Rouquié, "El misterio democrático: de las condiciones de la democracia a las democracias sin condiciones", en Cóno renacen las democracias. Emecé, 1985.
} 
políticas culturales. Finalmente, se proponen algunas hipótesis sobre el proyecto de hegemonía de la modemización autoritaria y desde allí los principales desafíos que hoy se visualizan para el proceso de redemocratización.

\section{REFLEXIONES SOBRE MODERNIZACIÓN Y MODERNIDAD}

"Scr moderno es encontramos en un entorno que nos promete aventuras, poder, alegría, desarrollo, transformación de nosotros y del mundo y que, al mismo tiempo, amenaza con destruir todo lo que tenemos, todo lo que conocemos, todo lo que somos. Los entornos y las experiencias modernas atraviesan todas las fronteras de la geografía y de la etnia, de la clase y la nacionalidad, de la religión y la idcología: se puede decir que en este sentido la modernidad une a toda la humanidad. Pero es una unidad paradójica, la unidad de la desunión: nos arroja a todos en una vorágine de perpetua desintegración y renovación, de lucha y contradicción, de ambigüedad y angustia. Ser modernos es formar parte de un universo en el que, como dijo Marx "todo lo sólido se evapora en el aire".

Marshall Berman².

Hoy, occidente vive un estadio de "alta modernidad", es decir, las consecuencias del modo de organización de la vida social que emerge en la Europa del siglo xvi han sido "radicalizadas y universalizadas"3. Su carácter radical sugiere un mundo heterogéneo y fragmentado pero con centros hegemónicos capaces de inducir cambios a cscala planetaria. Su alcance universal hace pensar que constituye un componente de cualquier cuadro institucional, pero con diferente contexto de significación conforme a las distintas unidades regionales o nacionales.

El tema de alta modernidad problematiza en el debate actual categorías de la teoría sociológica clásica, en especial las categorías de racionalidad y secularización. El discurso racional sccularizado es el resultado de un largo proceso de emancipación en la historia el pensamiento de occidente. La combinación racional y secular es producto del naturalismo en el pensamiento social del siglo de las luces o movimiento de la llustración. En esta tradición la modernización se enticnde como proceso de racionalización y desacralización del mundo con predominio de la racionalidad instrumental y desarrollo de fuentes de autoridad y lealtades alternativas a la religión y tcodicea tradicionales. El sentido de la razón ilustrada es axiomático en el paradigmá clásico de la modernización. En el estadio de alta modernidad, la razón ilustrada es objeto de revisión y crítica. La crítica apunta a poner en evidencia las insuficiencias epistemológicas y sustantivas de la racionalidad instrumental y a recuperar el carácter emancipatorio de la modernidad 4 .

La principal consecuencia de la modernidad es una compleja división internacional del trabajo, donde la transnacionalización de capital, mercados y tecnología presiona compulsivamente sobre las fronteras nacionales. Implícita a esta transnacionalización se da una globalización del modelo de desarrollo de la sociedad capitalista industrial: economía de mercado, organización intensiva en capital, apertura al comercio internacional y consumo de masas son los rasgos distintivos del modelo. En el estadio de alta modernidad, la globalización del modelo de desarrollo implica procesos de reconversión de largo alcance.

El mercado de consumo es aspecto dinámico del modelo y la creación de una cultura de masas

\footnotetext{
'Marshall Berman, Todo lo sólido se desvanece en el aire. La experiencia de la modernidad, siglo xxı Ed. 1988, 10.

Anthony Giddens, The Consequences of Modernity, Stanford University Press, Stanford Califomia, 1990.

- La escuela de Frankfurt levanta la crítica a la razón ilustrada. Ver al respecto, Max Horkheimer y Theodor Adorno,

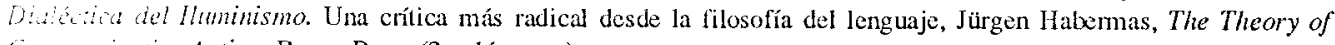
Commicutive Action, Bacon Press (2 volúmenes)
} 
es condición de su reproducción; ésta se vuelve una función especializada en la sociedad. Ámbito de instituciones y agentes profesionales, la cultura moderna se organiza en un sistema de máquinas productoras de "realidades simbólicas" que son transmitidas o comunicadas a los "públicos" o consumidores de bienes simbólicos. Las fronteras nacionales de la cultura desaparcen o se tornan permeables. El más poderoso mercado es, crecientemente, el "mercado de mensajes". "El individuo consumidor de ese universo simbólico se transforma en un experto hermeneuta: ser él mismo intérprete de las interpretaciones que circulan a su alrededor, traducir experiencias simbólicas producidas para él"5. En la alta modernidad se puede hipotetizar la figura de un "nuevo ciudadano", que lucha activa y reflexivamente por la resignificación y la apropiación simbólica o real de su entorno.

La información pasa a desempeñar un doble papel: fundamento de la acción y recurso de control social. Emerge así una ingeniería, donde la racionalidad técnica se construye en oposición contrafactual a la racionalidad de la dominación tradicional. La racionalidad técnica es particularmente rupturista en sociedades precapitalistas y estamentarias. El dominio de la información y la tocnología asociada hace que su manejo y utilización pasen a constituir símbolo de moder- nidad.

"Si América Latina es tributaria y es parte de la cultura occidental se debe a su incorporación en la experiencia de la modernidad. A su búsqueda, contradictoria, desigual, fracasada cien veces pero siempre retomada, de la inodernización y del modernismo, no sólo como fenómeno de sus intclectuales y tecnócratas, sino como proceso de masas. La manera latinoamericana de existir en la cultura occidental es en consecuencia por la experiencia cultural y cotidiana de una modernidad heterómana"'.

Se podría argumentar que el perfil de la modernidad aquí propuesto no constituye más que un remozamiento aparente del viejo paradigma de la modernización de los años 60 que ya probó su falta de realismo en siluaciones con agudas contradicciones de clase. En parte, así es en efecto. Sin embargo, la modernización de los años 60 apuntaba fundamentalmente a los procesos de cambio y su institucionalización en las estructuras de la economía y la sociedad. La modernidad en cambio, apunta hoy a las condiciones de posibilidad y a ese modo de experiencia vital descrito en nuestra introducción y que según Berman "es compartido por hombres y mujeres de todo el mundo". En este sentido la modernidad está lejos de aspirar a constituirse en un paradigma con carácter formal y estricto. En el estadio de alta modernidad expresa un énfasis por las cuestiones de la cultura y la sociedad. Además, la diferencia entre ayer y hoy es que este paradigma, no obstante las reservas académicas y su desprestigio en las ideologías de clase, ha servido como marco de articulación de viejas y nuevas categorías sociales y en cuanto modernidad ha tenido alta penetración en la lucha por la hegemonía social y política.

Para una discusión más extensiva y sistemática, centraremos el análisis en lo ocurrido en Chile bajo el régimen autoritario e inferir desde allí algunos desafíos actuales de la modernidad. Denominaremos a esta experiencia modemización autoritaria, pues el proceso de transformaciones se produce en el marco de una dictadura donde la institución militar monopoliza para sí y su bloque de poder la coerción y la capacidad de gestión de las políticas públicas ${ }^{7}$. La lectura de lo ocurrido se hará apoyándonos en los aprontes de intelectuales que representan distintos estilos de

\footnotetext{
${ }^{5}$ José Joaquín Brunner, Un Espejo Trizado, Salesianos, 1988. Pág. 24.

${ }^{6}$ Brunner, op. cit. Pág. 195.

${ }^{7}$ Para una discusión relativa a las distintas instancias de constitución de lo político, ver Raúl Atria, Estructura Social y Desarrollo Político: Un marco teórico de Análisis, en Atria y Matías Tagle Editores, Estado y Política en Chile, Corporación de Promoción Universitaria, 1991.
} 
pensamiento. En esta oportunidad haremos una discusión desde la apología neo-liberal y la crítica desde las políticas culturales.

\section{MODERNIZACIÓN AUTORITARIA: APOLOGÍA Y CRÍTICA}

El pensamiento neoliberal en Chile tiene una relación dialéctica de creador-criatura con la experiencia autoritaria. Antes del golpe militar ejerce un efecto de fuente de alternativa teórica a los proyectos de cambios implementados desde 1964 en la sociedad chilena. Con posterioridad al golpe, constituye un ingrediente fundamental al nuevo bloque en el poder y el régimen militar una oportunidad de laboratorio para implementar su proyecto de hegemonía conómica y política. No es extraño, por tanto, que hoy el pensamiento neoliberal se identifique ideológicamente con la experiencia autoritaria.

Más por su apología práctica que por definiciones teóricas, en el neoliberalismo la modernización se identifica con la norteamericanización y se asume a la sociedad norteamericana como una suerte de "utopía realizada", vale decir, como un estadio terminal del desarrollo ante el cual todas las sociedades de la tierra deben aspirar y como criterio de prueba o acreditación de los niveles de civilización logrados. Para los neoliberales, principalmente desde Norteamérica se producen "megatendencias liberalizadoras" que hoy recorren el mundo entero. Estas megatendencias han impulsado un dramático cambio en la economía mundial: cl tránsito de la "economía industrial" a la "economía de la información", tránsito que favorece particularmente a economías como la chilena, pues en la "economía de la información" el recurso relevante es el capital humano, y Chile, con sus elevados niveles de educación, está preparado para ingresar en esta nueva sociedad.

Según Lavin, "Chile se ha transformado en los últimos años, en un país capaz de atraer importantes inversiones extranjeras ${ }^{8}$. Como contraparte, para un número cada vez mayor de empresarios chilenos, los doce millones de habitantes del país ya no son el principal mercado para sus productos. La revolución del comercio exterior se ha traducido en un cambio total en la estructura de las exportaciones, reduciendo la importancia del cobre-que, en 1973 representó el $82 \%$ del total, en tanto que hoy llega sólo al 40\%-, y aumentando la de aquellos productos en que Chile tiene especiales ventajas comparativas, como la fruta, la madera y la pesca. Entre 1974 y 1986, las exportaciones totales se multiplicaron por dos; las agrícolas se multiplicaron por once, y las de frutas por veinticinco, llegando a casi 500 millones de dólares. Como el boom es reciente todo se ha desarrollado utilizando la más moderna tecnología". En frutas por ejemplo, el "último grito" de la tecnología mundial tiene un nombre: atmósfera controlada. A través de un sofisticado proceso que consiste en extraer el oxígeno reduciéndolo sólo a un dos por ciento, los frigoríficos de atmósfera controlada permiten que las manzanas, las peras y los kiwis se mantengan durante doce meses como si estuvieran recién cosechados.

En el orden interno, la clave de la revolución no habría sido el uso de la fuerza sino el poder de una idea - la libertad integral_ - promovida por un equipo comprometido con ella y dispuesto a dar la lucha por cambiar un país9. Según J. Piñera. Un nuevo Chile ha surgido como consecuencia de las reformas, de signo liberal llevadas a cabo entre 1974 y 1989: además de abrir la economía a la competencia internacional se privatizaron la mayoría de las empresas estatales; se eliminaron los monopolios empresariales y sindicales; se flexibilizó cl mercado de trabajo; se creó

\footnotetext{
${ }^{8}$ Para la exposición del perfil neoliberal en lo que sigue me apoyaré en el documento con relato de manifiesto de Joaquín Lavín, Chile revolución silenciosa, Lord Cochrane, 1989.

${ }^{9}$ José Piñera. El poder de una idea, artículo Diario El Mercurio, día 12 de julio de 1992, cuerpo D.
} 
un sistema privado de pensiones y de salud; se abrieron sectores enteros como el transporte, la energía, las telecomunicaciones y la minería a la competencia y a la iniciativa privada; se descentralizó la administración educacional y de salud; en fin se realizó una amplia tarea de desregulación y perfeccionamiento de los mercados, así como de apertura de áreas a la inversión privada. Una vez que maduraron estas reformas, el país creció a una tasa promedio anual de $6.3 \%$ en el quinquenio $85-89$ con aumento de la inversión a una tasa de $13.8 \%$, las exportaciones al ritmo de $9 \%$ y el empleo al $4.6 \%$ anual en ese mismo período.

Como es tradicional en los países a medida que se desarrollan, la fuerza de trabajo va siguiendo un conocido ciclo económico, que se inicia en la agricultura, para luego pasar a la industria y terminar en el sector servicios. Entre 1970 y 1986, el producto del sector agrícola creció en $54 \%$, en tanto que el número de personas ocupadas en la agricultura se redujo en 101 mil. Un proceso similar comienza a vivirse en las industrias, que ocupa hoy un porcentaje menor de la fuerza de trabajo que hace diez años.

La empresa chilena también está cambiando, forzada por la necesidad de competir, destacan la tendencia a la formación del holdings y a la subdivisión de los grandes conglomerados, la tendencia creciente a especializarse y a subcontratar otros servicios. En un número cada vez mayor de empresas, los trabajadores son, a su vez, accionistas, en tanto que un número creciente de compañías está otorgando a sus ejecutivos participación en la propiedad como parte de su remuneración. El fenómeno, bautizado en Chile como "capitalismo popular", está contribuyendo a la aparición de las grandes corporaciones, al estilo norteamericano, en que la propiedad está diluida entre miles de pequeños accionistas, ninguno de los cuales tiene influencia en el manejo de la empresa.

La revolución liberal ha producido polos de desarrollo. Cada vez se valora más la mayor calidad de vida ex istente en las regiones, con espacios abiertos, naturaleza, aire puro, tranquilidad, menor desempleo y... mejores oportunidades de negocios. Los problemas de Santiago, con su mayor tasa de desempleo, y la delincuencia y el hacinamiento en algunas poblaciones, están contribuyendo a detener la migración.

El resurgimiento del espíritu empresarial entre la juventud es un hecho. Pero por sobre todo, los empresarios han vuelto a ser líderes. El éxito empresarial trasciende hoy las fronteras, alcanzando un liderazgo en América Latina.

Uno de los mayores cambios que privilegian por cierto los neoliberales, lo constituye el intensivo "aprendizaje de economía" que ha recibido la opinión pública. Entre 1975 y 1986, más de 2.000 jóvenes chilenos viajaron a universidades norteamericanas o europeas a obtener un master o un doctorado, de los cuales una importante proporción lo hizo en ciencias relacionadas con la economía o la administración de empresas. El nivel de información económica luego de catorce años de libre mercado, es hoy significativo, ocupando espacios que los medios de comunicación masiva nunca antes habían otorgado, y obligándolos a crear secciones especializadas.

Un niño de quince años la destinado ya 10.000 horas de su vida a "extraer" información del televisor, lo que le abre un mundo de conocimientos que sus padres no tuvieron. Chile, transformado en el país con mayor relación de computadores por alumno en Latinoamérica, lo ha llevado ahora a encabezar el proceso de elaboración de software, es decir, de programas de computación educacional. Actualmente existen software para todos los cursos y materias desde el primer año de la Enseñanza General Básica hasta el último de la Enseñanza Media, y se ha iniciado su exportación a México, Argentina, Venezuela y Colombia.

Los chilenos comienzan paulatinamente a vivir con muchas más opciones que en el pasado. La sociedad de "esto o el otro", con dos o tres alternativas como máximo, ha sido superada por 
una nueva sociedad de "opciones múltiples", en que es posible elegir entre las más diversas posibilidades.

En síntesis, según los neoliberales la revolución liberal ha hecho posible que Chile pueda convertirse en un país plenamente desarrollado en la primera mitad del siglo xxı.

En términos del perfil propuesto en torno a la modernización y la modernidad, el pensamiento neoliberal reenfatiza el interés por la institucionalización del cambio en la economía y la sociedad. Asume explícitamente el modelo de la sociedad capitalista y la trasnacionalización de capitales, mercados y tecnologías como aspectos dinámicos de dicho modelo. Aboga por una ingeniería social con predominio de la racionalidad técnoinstrumental y cconómica. En suma, ideológicamente adhiere a la modernización como constructor racional secularizado y fucnte de legitimidad.

Una lectura muy distinta de la misma experiencia se está haciendo desde la perspectiva de la cultura. Desde ésta, según el decir de uno de sus principales exponentes ${ }^{10}$, el autoritarismo se inscribe en la hipótesis sobre la modernización y sus contradictorias manifestaciones de la cultura en América Latina: como proceso de descentramiento y fragmentación de la cultura. De este modo, la cultura pierde su capacidad de producir una imagen conceptual y de identidad integrada de la sociedad, ni puede proporcionar, en la práctica, un centro de cohesión y estabilidad a la economía, la política, la estructura social o incluso la nación y los mundos-de-vida-individuales. La cultura se ha hecho heterogénea y heterónoma: cl pastiche cultural, imitación, mímica de estilos y formas, de valores y contenidos, hecha con toda seriedad y como forma de cxperiencia impulsada por el mercado y el poder, por la difusión de modelos de necesidad y de consumo.

La crítica de la modernización autoritaria desde la cultura privilegia el ahálisis de las fomas de comunicación y el régimen comunicativo. Presume una estrecha relación entre el sistema político prevaleciente en una sociedad y el régimen comunicativo que aquel en parte condiciona y al cual necesita para subsistir. Esta relación se hace especialmente pertinente en Chile pucs, scgún Brunner, en nuestra experiencia contemporánea la cultura ha estado sobredeterminada por la política.

El régimen comunicativo de la sociedad chilena desde la ruptura del régimen oligárquico hasta 1973 se basó en la política, la ley y la escuela. Fue la expresión del predominio en el espacio público de las clases medias, con apego al formalismo legal, valoración de la enseñanza y uso de la política como medio de organización y fomento de la integración nacional.

"El Estado representó en Chile la encarnación de dicho régimen comunicativo. Fue un Estado providente, proteccionista, educador y uransaccional. Era un 'estado de compromiso' que propició la negociación entre clases y grupos sociales; promovió mediante la escuela, la ley y la política, la movilidad social ante todo la de las propias clases medias, y se afanó por distribuir las oportunidades de participación en la esfera pública de modo de asegurarse legitimidad, aunque no siempre obtuviera eficiencia. El Gobierno de la Unidad Popular exasperó y agotó la experiencia de ese estado de compromiso y debió reconocer al fin que la ley, la escuela y la política no eran medios para impulsar un proyecto revolucionario".

El régimen comunicativo del autoritarismo tiene sus raíces en el significado cultural del golpe militar, pues éste se presenta como reacción defensiva, socialmente compleja, de un cierto orden hegemónico amenazado por la experiencia revolucionaria desencadenada por la Unidad Popular. Pero, además, el golpe debe hacerse cargo del hecho que ese mismo orden hegemónico había

\footnotetext{
${ }^{10}$ Para la exposición crítica del enfoque de políticas culturales, ver José Brunner, op cit. de preferencia cap. Chile otro país ver también del mismo autor, Los debates sobre la modernidad y el futuro de América Latina, Flacso, Santiago de Clile, documento de trabajo, 1986.
} 
facilitado el triunfo y la acción transformadora de la Unidad Popular. Su objetivo no es, por tanto, meramente restaurador, es, por el contrario, "refundador". Así, lo que en un comienzo fue reacción defensiva, se convirtió en los años siguientes en un proyecto de refundación del orden sobre la base de nuevos dispositivos hegemónicos. En una empresa decididamente revolucionaria que a lo largo de una década ha intentado modificar los parámetros de funcionamiento de nuestra economía capitalista; cambiar las bases de organización del Estado; redefinir las relaciones de poder en la ciudad y en el campo; modificar el acceso de la población a los bienes y, en general, remodelar las bases de la nación. Los efectos de esta acción no han sido irrelevantes: se ha modificado profundamente la estructura de las clases sociales; la cconomía del país ha experimentado una drástica reconversión hacia afuera. Al mismo tiempo que los efectos de modernización logrados se combinan con una extensión de la cesantía y la pobreza, se han generado nuevas elites de poder y un sistema político excluyente que recurre sistemáticamente a la represión.

"El régimen autoritario instaurado en 1973 impuso a la sociedad chilena una nueva forma de comunicación con el empleo de medios de control social que combinan helerogéneamente los efectos del mercado, la represión y la televisión. Éstos conforman un medio público privatizado que gira en torno a la figura del consumidor y que valora la información, el 'exit' o comportamiento de salida y la movilización de proyectos individuales de bienestar. Mientras los medios del régimen democrático... tendían a generar relaciones estables, de identidad y sus relatos y ritos cran morales, los del autoritarismo, en cambio, generan relaciones fugaces, ocasionales, de proyección y sus relatos y ritos son técnicos".

Bajo el régimen comunicativo autoritario la comunicación social se asemeja más a un sistema técnico de condicionamientos operantes que a un mundo compartido de normas cuya legitimidad debe ser continuamente negociada. Mercado y represión son formas puramente fácticas de poder. Ambos dispositivos dibujan un horizonte mudo. La televisión, en fin, se utiliza como el gran medio que escenifica la vida privatizada, abriéndola a formas pervertidas de universalidad: la universalidad del mercado, con su capacidad de expresar los sueños adquisitivos ilimitados de la sociedad; la universalidad del poder autoritario, que vigila y denuncia, que estigmatiza y castiga, que enseña y oculta. Bajo este régimen de comunicación, la sociedad chilena se oculta a sí misma, se fragmenta, se disuelve lentamente en medio del fraccionamiento, de las querellas y traumas, del miedo y la ausencia de un identidad nacional compartible.

"Mirado en perspectiva, el régimen militar significó, desde las políticas culturales, cuatro fenómenos cuyos efectos se combinan y refuerzan mutuamente: 1. El Estado abandona su papel de promotor y difusor de la cultura entregando la regulación de los procesos comunicativos a los circuitos privados coordinados por el mercado; 2. El Estado se reserva, en cambio, las funciones de control ideológicos y administrativo de dichos procesos e interviene para ello activamente en la reorganización de los aparatos culturales; 3 . El espacio público de la comunicación pierde su carácter competitivo entre posiciones que pugnan por el predominio en el terreno ideal. Los conflictos culturales se privatizan y la producción de sentidos públicos pasa a ser administrada por agentes y órganos ideológicos del nuevo bloque en el poder; 4. Simultáneamente durante el período se amplían las bases de la recepción privada de los bienes culturales: por el explosivo incremento de la televisión y en virtud de la expansión escolar producida a partir de 1965 cuyos efectos se manifiestan recién ahora".

La crítica al proceso de modernización como condición heterónoma de descentramiento y fragmentación de la cultura hace pensar que el enfoque de las políticas culturales sospecha por definición de toda modalidad (racionalidad) de modernización o modernismo. Sin embargo, el uso del término régimen comunicativo bajo distintos universos de significación posibles permite hipotetizar a la modernización como proyecto inacabado y un rescate y reforma a la propia 
modernidad a lo Habermas. En esta perspectiva es congruente con este enfoque proponer una "reapropiación" social de las orientaciones no sólo de la cultura y sus distintos ámbitos autonomizados - ciencia, moralidad y arte- sino de todo el proceso de modernización, mediante instituciones que pongan límite a la dinámica interna y a los imperativos de un sistema económico casi autónomo y sus complementos administrativos" 1 .

En el horizonte de la modernidad estas instituciones están referidas de preferencia al proceso de construcción y desarrollo de la democracia, al fortalecimiento de las instituciones de la sociedad civil y a la nueva relevancia que adquiere en el proceso el campo de la cultura y las políticas culturales.

\section{MODERNIZACIÓN AUTORITARIA Y REDEMOCRATIZACIÓN. PROSPECTIVA}

En las páginas anteriores se han desarrollado como punto de partida dos formulaciones sustancialmente antagónicas frente a la experiencia de la modemización autoritaria.

La única coincidencia entre los aprontes discutidos es en torno al efecto revolucionario de dicha modernización. De hecho, este efecto sólo podría ser comparado en la historia de Chile del siglo xx con las transformaciones que llevaron a la cancelación o término del régimen oligárquico en la década de los años 20. De este modo, el proyecto de refundación del régimen autoritario tuvo que pasar necesariamente por replantear los términos de una nueva hegemonía.

Asumiendo el valor heurístico de la categoría régimen comunicativo, estimo que los expedientes del mercado, la represión y la tclevisión no dan cuenta cabal de la propuesta de hegemonía del régimen militar. Subyacente a tales expedientes y componente unificador de la acción se da el elemento sustancial a la nueva hegemonía: un amplio programa de resocialización de la población vis-a-vis la institucionalización de la motivación y el éxito económico. En la lógica de una resocialización tolal, la modernización autoritaria erige al mercado como ente regulador y racionalizador de la vida social construyendo el escenario figurado de formación y desarrollo del "homo economicus", abstracción neoclásica del actor racional.

El "homo economicus", en efecto, es una figura abstracta de la economía neoclásica, hedonista por antonomasia y que busca la maximización del beneficio o la ganancia. Organizado conforme a sistema operante de estímulo-respuesta reconoce básicamente un repertorio de motivos muy simple y elemental: referidos a la subsistencia, la diversión o entretenimiento y al autorrespeto y expansión del ego. La mayor o menor complejidad de la figura depende del carácter de los estímulos, la exposición a éstos y su saldo en el balance de costos y beneficios.

$\mathrm{El}$ "homo economicus" adquiere su mayor plausibilidad empírica en la empresa y en particular el empresario capitalista, cuyo propósito manifiesto es el de la ganancia o beneficio económico. Sin embargo, en términos genéricos constituye un constructo económico, hipótesis o arquetipo de conducta, imputación de racionalidad a toda conducta motivada por el cálculo y el éxito cconómico. Así, este constructo tiene la particularidad de desvanecer en un denominador común a cualquier categoría social o identidad histórica: su portador puede ser simultánea o sucesivamente empresario o trabajador, consumidor u observador, artisla o funcionario. En su escenario de referencia, los individuos o grupos pasan a constituir una planilla de sueldos, un listado de clientes o los últimos benefactores de la humanidad.

Reducidas las relaciones sociales a la hipótesis del "homo economicus" como actor racional

${ }^{11}$ Jürgen Habermas. La Modernidad, un proyecto incompleto, en Hal Foster, La past-modernidad, Editorial Kairós Barcelona, 1985, pág. 24. 
en búsqueda de la maximización del beneficio, éste se constituye en el fundamento de una teoría relativa a la asignación óptima de recursos, la teoría de la utilidad marginal. En el marco de la teoría, el beneficio es función de decisiones relacionadas a curvas de satisfacción. Esta teoría, reificada, emite sistema de mensajes supuestamente transparentes formado por los precios relativos de factores de producción, bienes y servicios. Bajo determinadas condiciones de oferta de bienes y servicios, el sistema de precios proporciona mediciones sincréticas de curvas de satisfacción y oferta. Digo que la teoría es reificada por cuanto cancela cl carácter intersubjetivo propio de las relaciones sociales y supone relaciones puramente físicas, "objetivas" e inalterables entre cosas.

El sistema de mensajes señalado y sus fundamentos configuró el principal si no único guión hermenéutico de la modernización autoritaria. Entre la teoría abstracta y el guión portado por los actores existen por cierto múltiples mediaciones institucionales. La más proxima a los actores es la escenificación de pautas de conducta tipo, vía medios de comunicación de masas. La manipulación de símbolos de status asociados a las decisiones de los actores es el instrumento de codificación del guión hermenéutico para los efectos de interpretación y nexo entre creación de aspiraciones y alternativas de satisfacción de los actores.

La codificación más básica y genérica pasa por la reducción de los actores a consumidores. Pero se dan códigos también para usuarios de servicios especiales en salud y previsión social, ahorrantes, inversionistas, etc. Vale decir, el "homo economicus" se despliega en una multiplicidad de situaciones ante la "universalidad del mercado y su capacidad de exaltar y satisfacer los sueños adquisitivos ilimitados de la sociedad".

El carácter hedonista y unidimensional del guión hermencutico hace posible que su portador o agente esté libre de toda contingcncia moral. Puede tratarse de institución de beneficiencia o red de narcotraficantes. Otro tanto ocurre en el plano expresivo-estético. De hecho, poco importa la bondad o belleza del negocio. Lo importante es el éxito, el cual pasa por la realización del grupo-objetivo y el ajuste de costos y beneficios ${ }^{12}$.

El guión hermenéutico como pauta de resocialización total contó con el apoyo reproductivo desde el Estado autoritario. En correspondencia con la teoría, el Estado acomete la tarea de creación de ambiente propicio para el desarrollo del "homo economicus", en particular en el control de las variables no económicas. Los expedientes represivos, en consecuencia, pueden ser visualizados como recursos orientados a mantener las variables no económicas con rangos de valores constantes ("ceteris paribus").

Pero la viabilidad del programa de resocialización esbozado es contingente también a que el "homo economicus" tenga espacio de desarrollo autónomo, es decir, abrir "sectores enteros a la competencia y la iniciativa privada" De este modo, la institucionalización de la motivación y el éxito económico se completó "abriendo áreas a la inversión privada" mcdiante el uso de distintos mecanismos: en un comienzo a través del blanqueo de capitales; en situaciones de crisis, asumiendo el Estado la responsabilidad por la deuda privada; pero durante todo el período autoritario vía transferencia de patrimonio y servicios, en consecuencia de autoridad y poder, desde cl Estado al sector privado.

La transferencia de patrimonio se inicia desde la instalación del régimen militar. Mediante la devolución de empresas requisadas o intervenidas por el Gobierno de la Unidad Popular, en seguida privatizando las compañías y bancos adquiridos por el Estado durante la administración

\footnotetext{
${ }^{12}$ Si mentalmente se aísla la indiferencia ética del "homo econonicus" de los expedientes represivos del régimen militar, se logra desde la modernización autoritaria una fuente explicativa de un hecho que numerosos analistas hemos señalado: que con la experiencia autoritaria la sociedad chilena redujo notablemente su capacidad de asombro.
} 
anterior. Por este último concepto, entre 1974 y fines de esa década se traspasó al sector privado la propiedad accionaria de unas 500 empresas. La segunda ronda de traspasos comienza en 1984, reprivatizando empresas y bancos cuyo control había sido asumido por el Estado en la crisis de 1981-83, que se conoció como "área rara" de la economía. Se estima que en cada una de estas operaciones se vieron involucrados alrededor de mil millones de dólares ${ }^{13}$.

Pero fue en 1985 cuando el Gobierno militar anuncia programa de venta accionaria de empresas públicas, que recaería fundamentalmente en los fondos de pensiones (AFP). La diferencia de este programa con las rondas de traspasos anteriores es que si bien incluye un número menor de empresas, éstas son las mayores del país en sus respectivos rubros. Hacia 1989 dieciocho empresas habían sido vendidas completamente y otras siete seguían el mismo camino. Para las 33 unidades envueltas en el proceso, la participación privada alcanzaría en promedio un $85 \%$ y ésta no se encuentra limitada a las AFP, sino que sc extendió a capitales nacionales y extranjeros y en algunos casos a los trabajadores. Se estima oficialmente que la recaudación fiscal obtenida con este programa alcanza a los us\$ 1.700 millones $^{14}$. En este documento se adjunta informe sobre empresas públicas en proceso de privatización a marzo de 1989, elaborado por Mario Marcel.

Con respecto a la transferencia de servicios del sector público éste incluye la creación de un sistema privado de pensiones y salud; más que transferencia propiamente tal se trata de la apropiación por parte del sector privado de actividades tradicionalınente monopolizadas por el Estado. Finalmente, otra figura utilizada fue la subcontratación de servicios que las empresas públicas realizaban valiéndose de unidad administrativa propia. Esta figura se utilizó masivamente para reducir personal de las empresas públicas no privatizadas y de la administración pública en general. Por tratarse de decisiones de unidades administrativas descentralizadas no se dispone de información global confiable.

La distancia y contradicción entre los estilos de pensamiento discutido en este documento pone en evidencia un hecho que es preciso tener en cuenta para el proceso de redemocratización en Chile: que la modernización autoritaria representó una profunda ruptura en el mundo de significaciones entre grupos y clases sociales. Mientras unos reivindican la revolución en nombre de megatendencias liberalizadoras; otros acusan la existencia de un medio de represión que disuelva toda identidad nacional compartible. A partir del tenor sustantivo de este documento la ruptura de significación anotada responde al hecho que para algunos sectores, principalmente vinculados al capital y su base social, el programa de resocialización centrado en el "homo economicus" constituyó el apoyo estratégico para el despliegue coherente de su proyecto modernizador; para otros sectores, por el contrario, principalmente clases dependientes y asalariados, el programa implicó profundas e insalvables externalidades en el estricto sentido durkheimiano y sociológico del término. Estas externalidades expresan el carácter mayoritariamente excluyente del programa de resocialización y en torno a ellas se articularon formas de resistencia ideológicas y políticas que hicieron posible el proceso de retorno a la democracia. Adicionalmente, se han constituido también en cristalización de demandas sociales que presionan en el sentido de una redemocratización sustantiva, esto es, incluyendo derechos no sólo político-formales, sino que derechos humanos, económicos y sociales ${ }^{15}$. De estas hipótesis se deduce que si el proceso de redemocratización no atiende cstas demandas sustantivas cabe esperar un ambiente social y

\footnotetext{
${ }^{13}$ Mario Marcel, Privatización y Finanzas Públicas, en Colección Estudios CIEPLAN N²6, junio 1989.

${ }^{14} \mathrm{Marcel}$, op cit. Ver también Hachette, D. y R. Lüders, El proceso de privatización en Chile desde 1984, en Boletín Económico № 24, Facultad de Ciencias Económicas y Administrativas, Pontificia Universidad Católica de Chile.

${ }^{15}$ Para una discusión más amplia sobre los temas de democracia y democratización, ver Manuel Antonio Garretón Reconstruir la politica, Editorial Andante, 1987.
} 
$\therefore$ ¿co con anomia altamente generalizadas. En lo cotidiano, no adhesión ni resistencia, indife-

Otro aspecto relevante en la perspectiva de la redemocratización es el eventual quiebre que . $\therefore$ a el supuesto isomorfismo entre modernización y democracia en la historia del pensamiento

- al. En efecto, el liberalismo clásico presume una correspondencia necesaria entre capitalismo : mocracia. La democracia se basa en la soberanía nacional y la asamblea constituyente es el . institucional de la soberanía popular. En la tradición del liberalismo se asume la asamblea situyente como fuente de poder único e indisoluble. Incluso desde la tradición crítica marxista - :onoce esta relación. "Una república democrática, escribe Lenin, es el mejor terreno político ible para el capitalismo"16. El neoliberalismo criollo tiene que hacerse cargo del hecho que la lución capitalista se produce bajo las reglas autoritarias de una dictadura militar. De aquí que pología del neoliberalismo al proceso de modernización sólo hace posible alusiones condicio¿s a la democracia y apostar congruentemente a una especie de "ciudadano consumidor que $\therefore$ cotidianamente en el inercado"17. Esta suerte de "democracia directa" tiene, por cicrto, poco $\therefore$ ver con la fuente de poder unívoco de la democracia representativa clásica. La ausencia de mortismo entre proyectos de modernización y democracia anticipa un factor de tensión - vológica e institucional en el proceso de construcción democrática en curso.

Pero la principal fuente de desafíos para la redemocratización deviene del hecho que la dernización autoritaria constituyó un cambio estructural en las relaciones entre economía y ciedad. La institucionalización de la motivación y el éxito económico se apoyó en una transfe- acia de autoridad y poder desde el Estado al sector privado, con la consiguiente liberalización $\because$ las relaciones de trabajo. Este proceso implicó "un cambio fundamental en la relación salarial, scle una situación de protección del trabajador hacia una situación de laissez-faire en materia de Liarios y contratos colectivos. La modificación de la relación salarial se tradujo en una devaluaSón social y económica del conjunto de la clase trabajadora"18. La actual significación estructural il sector privado y la asimetría capital-trabajo en la empresa y la economía replantea criterios de iferenciación e integración entre lo público y lo privado, entre Estado y sociedad civil y, por tanto, undiciona las instancias de reconstitución democrática.

El retorno a la democracia en Chile se la dado en el marco de una constitución plebiscitada en 1980 por el régimen autoritario y cuyas normas expresan el espíritu de una "democracia protegida". El tránsito a la democracia, en consecuencia, ha requerido de alta ingeniería marcada for una política de acuerdos y formación de consensos en torno a tópicos específicos. En este proceso el bloque de poder identificado con el régimen autoritario ha jugado un rol significativo. Supuestos estos antecedentes cabc concluir este documento formulando las siguientes preguntas: Las modificaciones producidas por la modenización autoritaria en especial en materia de institucionalización de la motivación y el éxito económico ¿constituyen parte consolidada del proceso de redemocratización? La falta de isomorfismo entre modernización y democracia ¿es peculiar al neoliberalismo criollo o se da también en otras fuerzas políticas relevantes? ¿Qué está ocurriendo y cuáles son las probabilidades de profundizar las demandas por derechos económicos y sociales? Estas preguntas configuran el límite de esta exposición y abren importantes interrogantes a la investigación teórico-empírica.

\footnotetext{
${ }^{16}$ Lenin, en Stanley W. Moore, The Critique of Capitalist Democracy, Paine Witman Publisher, N.Y. 1957 pág. 84.

${ }^{17}$ Joaquín Lavin, op cit. pág. 68.

${ }^{18}$ Cecilia Montero, Crisis del Empleo y Relaciones sociales, en Francisco Zapata compilador, Clases sociales y acción obrera en Chile, El Colegio de México, D.F. 1986, pág. 60.
} 


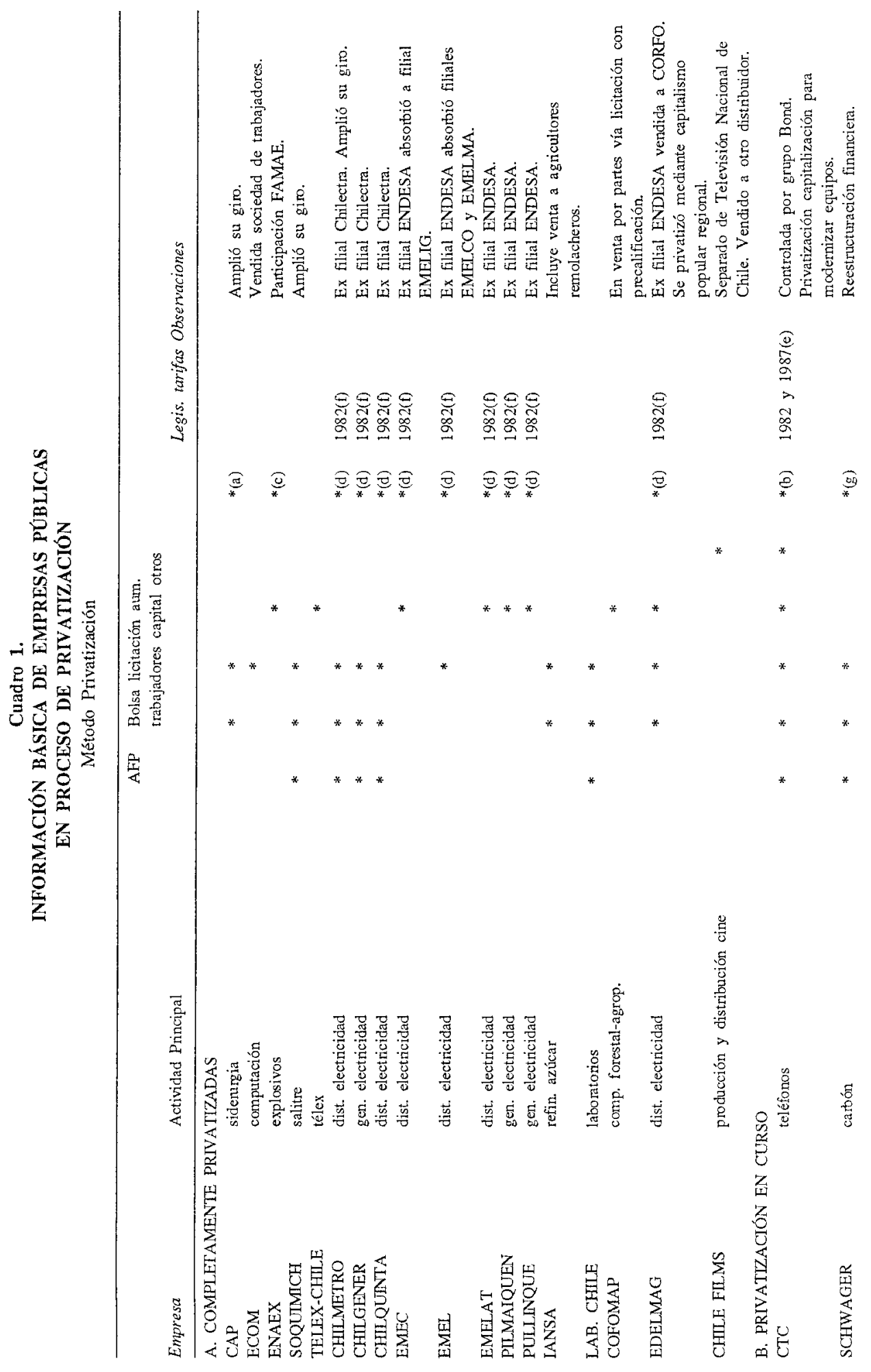



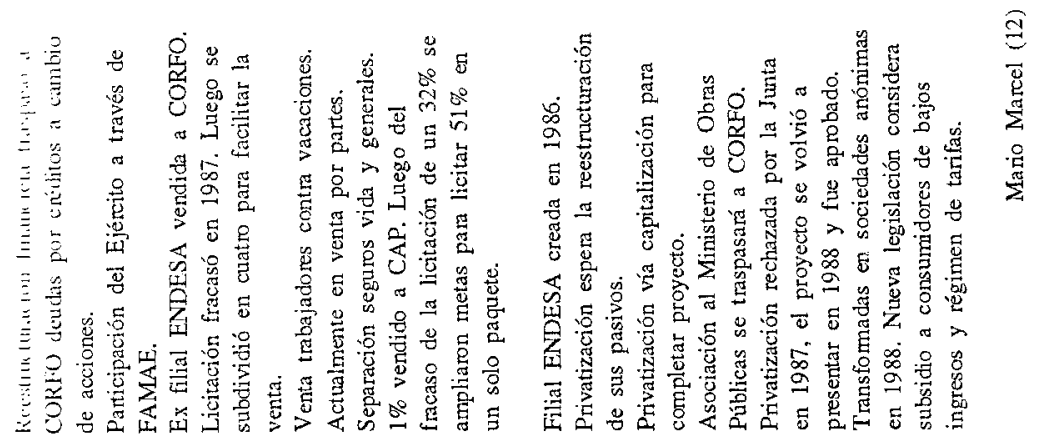

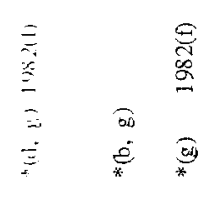
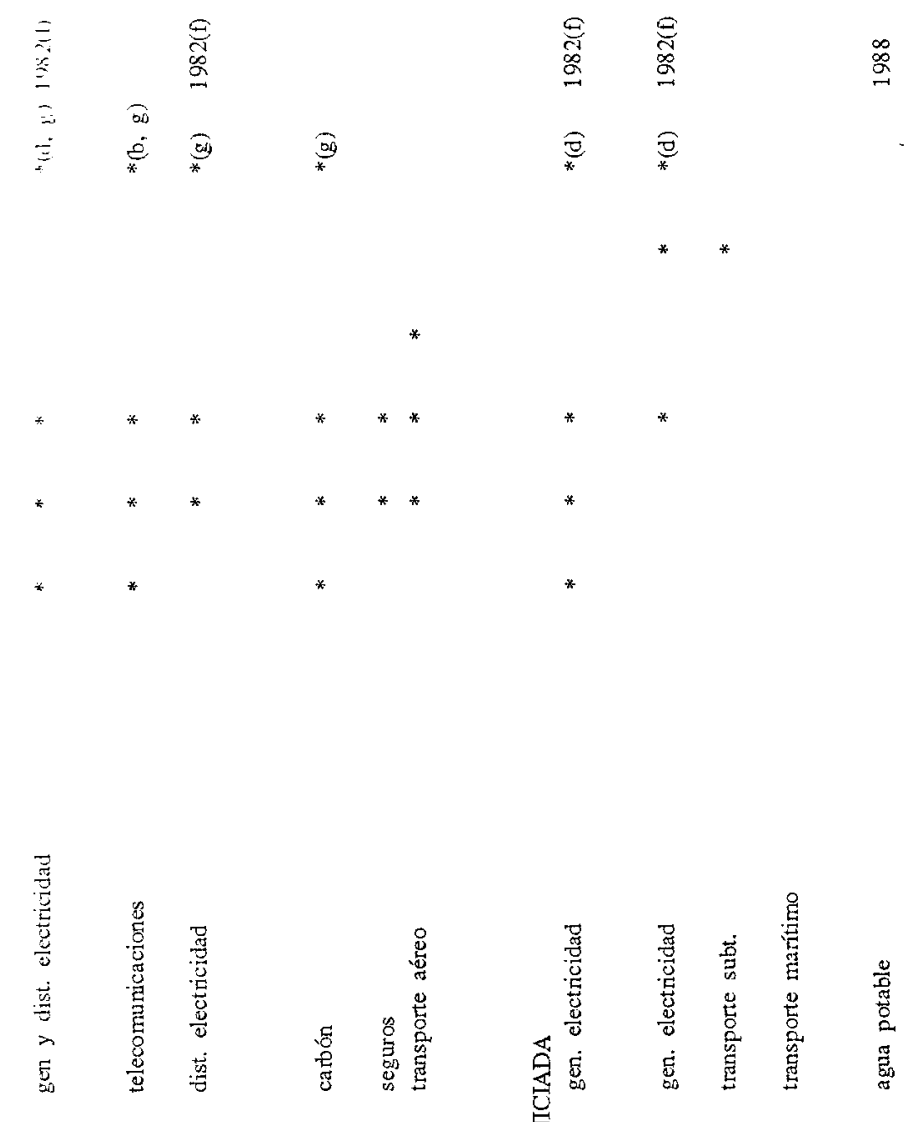

*

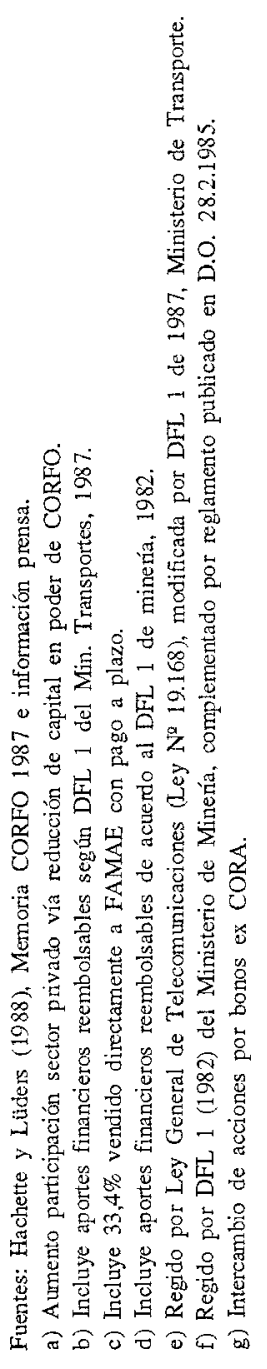

